\title{
SCALING EFFECT ON MEMS-BASED MICROBIAL FUEL CELLS: TOWARD A CARBON-NEUTRAL MINIATURIZED POWER SOURCE
}

\author{
H. Ren and J. Chae
}

School of Electrical, Computer and Energy Engineering, Arizona State University, Tempe, Arizona, USA

\begin{abstract}
We report the scaling effect on a $\mu \mathrm{L}$-scale miniaturized microbial fuel cell (MFC), gearing toward a carbon-neutral miniaturized power source. MFCs have been studied for many years, yet the scaling effect on MFCs has not been addressed effectively in the past. This work studies the scaling effect on mass transfer to improve the power density of a $\mu \mathrm{L}$-scale MFC. As scaling down the characteristic length, Reynolds number decreases and mass transfer coefficient rapidly increases, resulting in a higher power density. Areal and volumetric power densities of $83 \mu \mathrm{W} / \mathrm{cm}^{2}$ and 3.32 $\mathrm{mW} / \mathrm{cm}^{3}$ are obtained, respectively; both of which the highest ever reported among all $\mu \mathrm{L}$-scale MFCs to date. Columbic efficiency (CE) of $79.4 \%$ is marked, more than 2.5 folds of the previously reported maximum $\mathrm{CE}$ in $\mu \mathrm{L}$-scale MFCs.
\end{abstract}

\section{INTRODUCTION}

In the era of energy crisis, renewable power sources, including solar/hydro power, geothermal energy, etc., become very attractive. One of such renewable power sources is a microbial fuel cell (MFC) harvesting electricity from biomass. A MFC is an electrochemical fuel cell harvesting electrons from specific bacteria species, exoelectrogen, via their extracellular electron transfer (EET). Unlike other approaches to convert biomass to electricity, including methanogenic anaerobic digestion, bioethanol, incineration and gasification etc., MFC is unique to have direct electricity generation with high conversion efficiency, to operate at low organic concentration and environmentally unfriendly conditions and to generate reduced amount of sludge. MFCs have been proposed to be used in scaled-up wastewater treatment and renewable energy production [1-3], bioremediation of recalcitrant component [4-6] and power supply for remote sensors in hazard or environmentally unfriendly conditions [7-8]. Miniaturizing MFCs is an interesting approach as scaling effects on the characteristic length largely impact several performance parameters of MFCs. Our prior work [9] presents one of highest areal power density, up to $33 \mu \mathrm{W} / \mathrm{cm}^{2}$, in a $\mu \mathrm{L}$-scale MFC, yet it is still far lower than that of macro-/meso-scale counterparts (up to $680 \mu \mathrm{W} / \mathrm{cm}^{2}$ ).

We report scaling down its characteristic length of a $\mu \mathrm{L}-$ scale MFC, resulting in increasing the mass transfer coefficient, consequently enhancing power density and efficiency of MFC. The maximum areal and volumetric power density of a MFC can be written as:

$$
\begin{gathered}
p_{\text {max }, \text { areal }}=\frac{P_{\max }}{A}=\frac{E_{O C V}{ }^{2}}{4 R_{i} \cdot A} \\
p_{\text {max, volumetric }}=\frac{P_{\max }}{V}=\frac{E_{O C V}{ }^{2}}{4 R_{i} \cdot V}=\frac{E_{O C V}{ }^{2}}{4 R_{i} \cdot A} \cdot S A V
\end{gathered}
$$

where $p_{\max , \text { areal }}, p_{\max , \text { volumetric }}, P_{\max }, E_{\text {ocv }}, R_{i}, A, V$ and $S A V$ are the maximum areal power density, maximum volumetric power density, maximum power, open circuit voltage, internal resistance, area, chamber volume and surface area to volume ratio, respectively. For a given type of MFC, as open circuit voltage (OCV) and the product of $R_{i}$ and $A$ are constant, the areal power density is independent of the scaling effect whereas $S A V$ increases as scaling down the characteristic length, resulting in the enhancement of volumetric power density.

In addition to these parameters, miniaturized MFCs benefit from higher mass transfer [11]. Reynolds number, $R_{e}$, and mass transfer coefficient, $k_{c}$, can be written as:

$$
\begin{gathered}
\mathrm{R}_{e}=\rho v L / \mu \\
k_{c}=0.664(\rho v L / \mu)^{1 / 2}(\mu / \rho D)^{1 / 3}\left(\frac{D}{L}\right)
\end{gathered}
$$

where $\rho, v, L, \mu$, and $D$ are the specific density of the fluid, the linear velocity of the fluid, the characteristic length, the viscosity of the fluid, and the diffusivity of the fluid. As shown in figure 1, by scaling down the characteristic length while making other parameters remain unchanged, the Reynolds number decreases and the mass transfer coefficient increases.

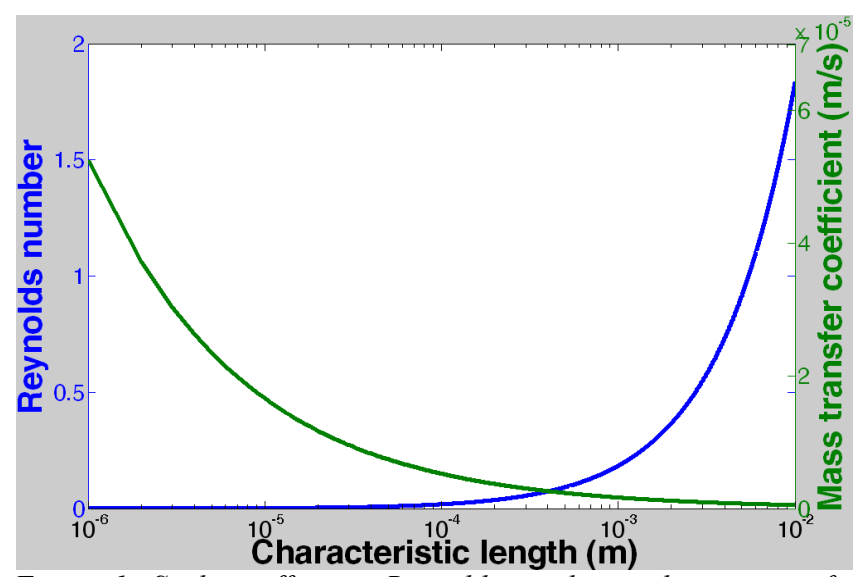

Figure 1: Scaling effect on Reynolds number and mass transfer coefficient; moving from $1 \mathrm{~mm}$ to $1 \mu \mathrm{m}$ in the characteristic length lowers Reynolds number from 0.18 to $1.8 \times 10^{-4}$ and enhances the mass transfer coefficient from $1.7 \times 10^{-6}$ to $5.2 \times 10^{-5} \mathrm{~m} / \mathrm{s}$.

\section{MATERIALS AND METHODS}

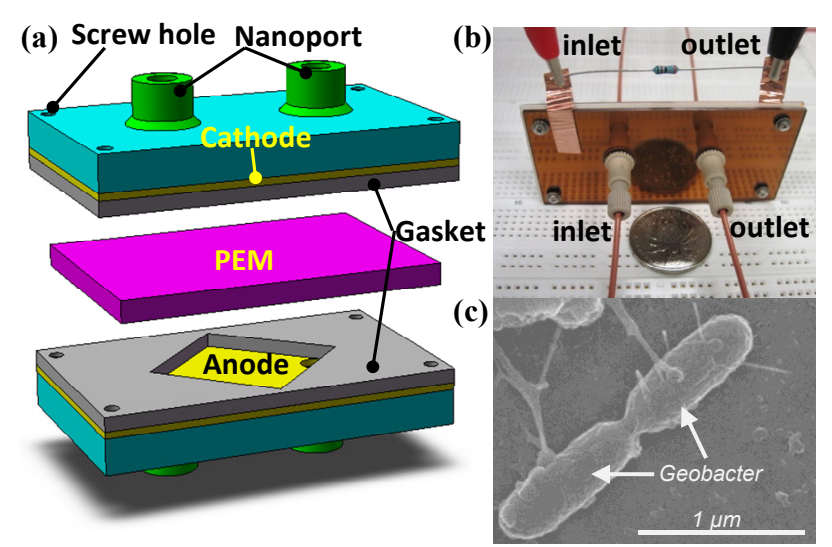

Figure 2: (a) Schematic of a $\mu$ L-scale microbial fuel cell (MFC); anode and cathode sandwich an ion exchange membrane and gaskets define the height of anode/cathode chambers. (b) photograph of a fabricated $\mu L$-scale MFC, and (c) SEM of Geobacter on the anode (scale bar: $1 \mu \mathrm{m}$ ).

The schematic of $\mu \mathrm{L}$-scale MFC is illustrated in figure 2(a).

Solid-State Sensors, Actuators, and Microsystems Workshop Hilton Head Island, South Carolina, June 3-7, 2012 
The MFC has a proton exchange membrane (PEM) and two silicone gaskets sandwiched between two glass slides pre-fabricated with gold electrodes. The volume of each chamber is $100 \mu \mathrm{L}$ and the size of electrode is $4 \mathrm{~cm}^{2}$. Two nanoports (10-32 Coned assembly, IDEX Health \& Science) were used to provide microfluidic pathways for the MFC. The fabrication process begins with preparing two glass chips $\left(76 \times 38 \times 0.12 \mathrm{~cm}^{3}, \mathrm{VWR}\right)$ and mechanically drilling six through holes on each chip: one inlet, one outlet, and four for assembly. Afterwards, Cr/Au (20 nm/200 nm) were deposited by sputtering on the anode/cathode. Then, the nanoports and fluidic tubings (PEEK polymer, IDEX Health \& Science) were aligned and glued to the inlets/outlets to supply anolyte and catholyte. Silicone rubber gaskets were cut to define the chamber and electrode and PEM (Nafion 117) was used as a membrane to permit only proton transport and avoid electrical short-circuit and electrolyte cross mix. Finally the MFC was assembled using four screw bolts and nuts to minimize oxygen/electrolyte leakage (figure 2(b)). SEM photograph shows Geobacter on the anode (figure 2(c)), allowing high current density $\left(>10 \mathrm{~A} / \mathrm{m}^{2}\right)[12]$.

The inoculum for the $\mu \mathrm{L}$-scale MFC was obtained from an acetate-fed microbial electrolysis cell (MEC) [14] that had Geobacter-enriched mixed bacterial culture from anaerobic digestion sludge. Clone libraries of the 16S-rRNA gene showed that the inoculum was a mixed bacterial culture dominated by Geobacter sulfurreducens [14]. The anolyte and catholyte are $25 \mathrm{mM}$ sodium acetate medium and $50 \mathrm{mM}$ potassium ferricyanide in $100 \mathrm{mM}$ phosphate buffer solution ( $\mathrm{pH} 7.4)$, respectively. The anolyte and catholyte were supplied into the $\mu \mathrm{L}$-scale MFC using a syringe pump (Cole-Parmers Inc.).

Acetate in the anode chamber is oxidized by Geobacter to carbon dioxide and release electrons and protons:

$$
\mathrm{CH}_{3} \mathrm{COO}^{-}+2 \mathrm{H}_{2} \mathrm{O} \rightarrow 2 \mathrm{CO}_{2}+8 \mathrm{e}^{-}+7 \mathrm{H}^{+}
$$

These electrons are transferred to the anode, pass through an external circuit to arrive the cathode, and are reduced by ferricyanide:

$$
\left[\mathrm{Fe}(\mathrm{CN})_{6}\right]^{3-}+\mathrm{e}^{-} \rightarrow\left[\mathrm{Fe}(\mathrm{CN})_{6}\right]^{4}
$$

The current was monitored every minute by recording voltage drop across an external resistor connected between the anode and the cathode using a data acquisition system (DAQ/68, National Instrument). $148-\Omega$ resistor was used during the start-up and a series of resistors, ranging from $148 \Omega$ to $932 \mathrm{k} \Omega$, was used to obtain the polarization curve of the $\mu \mathrm{L}$-scale MFC, respectively. The current through the resistor was calculated via Ohm's law $(I=V / R)$ and the resulting output power was calculated via Joule's law $\left(P=I^{2} R\right)$.

\section{RESULTS AND DISCUSSION}

The $\mu \mathrm{L}$-scale MFC operated in a semi-continuous mode at 1 $\mu \mathrm{L} / \mathrm{min}$ using anolyte with inoculum (1:1 volume ratio) and catholyte during the start-up process. Figure 3 shows the $\mu \mathrm{L}$-scale MFC reached $>1.8 \mu \mathrm{A} / \mathrm{cm}^{2}, 4$ days after the operation. Then, the current density increased quickly. When the current density reached $20 \mu \mathrm{A} / \mathrm{cm}^{2}$ on the sixth day it began to fluctuate due to cathode-limited MFC condition, which diminished by supplying more catholyte.

Mass transfer is a function of the concentration and linear velocity of electrolyte (Eq. (4)). The concentration of anolyte and catholyte increased from $25 \mathrm{mM}$ to $37.5 \mathrm{mM}$ and $50 \mathrm{mM}$. The concentration increase did not result in enhanced areal power density; contradictory to the prediction that higher concentration induces higher mass transfer, which subsequently resulting in higher power density. A possible reason for this is that a high concentration causes bacteria to dehydrate, which results in lower power densities [15].

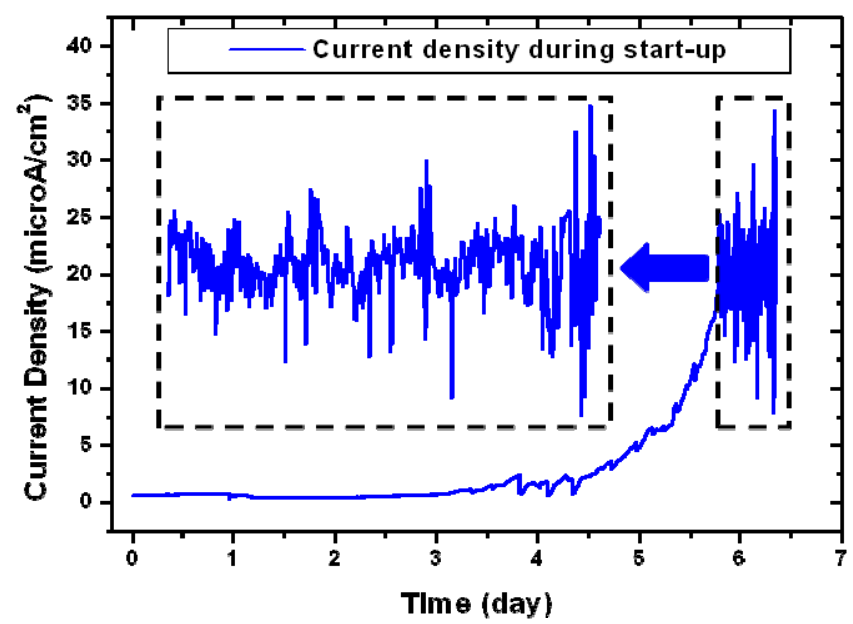

Figure 3: Current density produced by the $\mu L$-scale MFC during the start-up process; the current density began to increase above 1.8 $\mu A / \mathrm{cm}^{2}, 4$ days after adding inoculum, and increased quickly with time, and began to fluctuate once it reached $20 \mu \mathrm{A} / \mathrm{cm}^{2}$. The fluctuation is due to cathode-limited MFC condition, which diminished by supplying more catholyte.

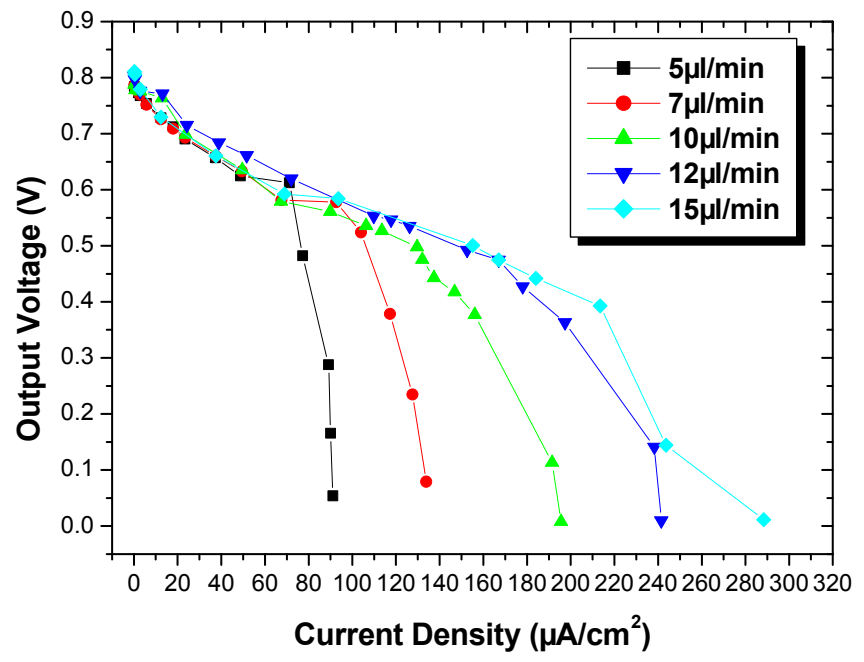

Figure 4: Output voltage versus current density at different flow rates from 5 to $15 \mu \mathrm{L} / \mathrm{min}$. As the flow rate increases the maximum current density increases, suggesting mass transfer improves as the flow rate increases.

The linear velocity of electrolyte was controlled by the flow rate of external syringe pump. The flow rate increased from 1 to 15 $\mu \mathrm{L} / \mathrm{min}$ to study the impact of mass transfer on power densities (figure $4,5 \& 6$ ). The increase in power density can be attributed from higher mass transfer of anolyte and buffer into biofilms, providing more acetate to the bacteria, resulting in a higher power density. The curves of the areal power density as a function of current density for different flow rates, figure 5, suggest that the areal power densities are almost independent of flow rates at low current densities, and increase as the flow rate increases. As the current densities increase, the areal power density of lowest flow rate firstly hit its maximum, which is due to the high concentration 
loss, while the areal power densities of highest flow rate hits its maximum lastly. This suggests the high flow rate keeps the $\mu \mathrm{L}$-scale MFC from suffering concentration loss at high current densities.

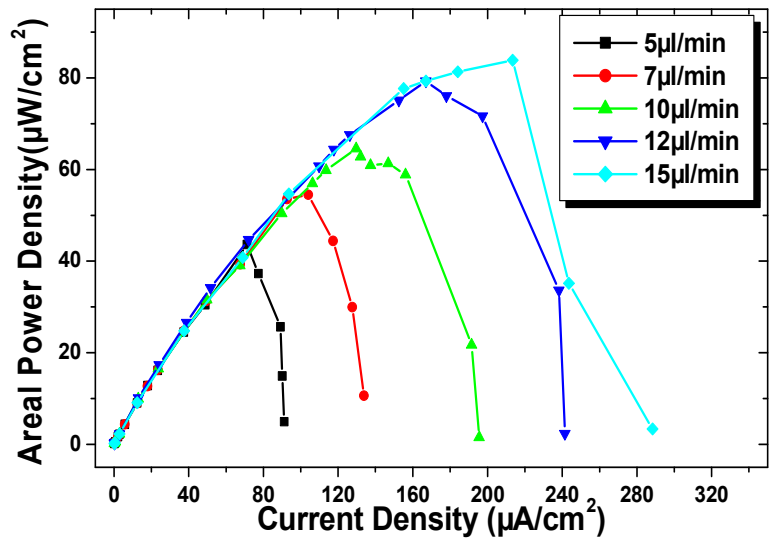

Figure 5: Areal power density versus current density at different flow rates; as the flow rate increased, both the maximum current and power densities improved.

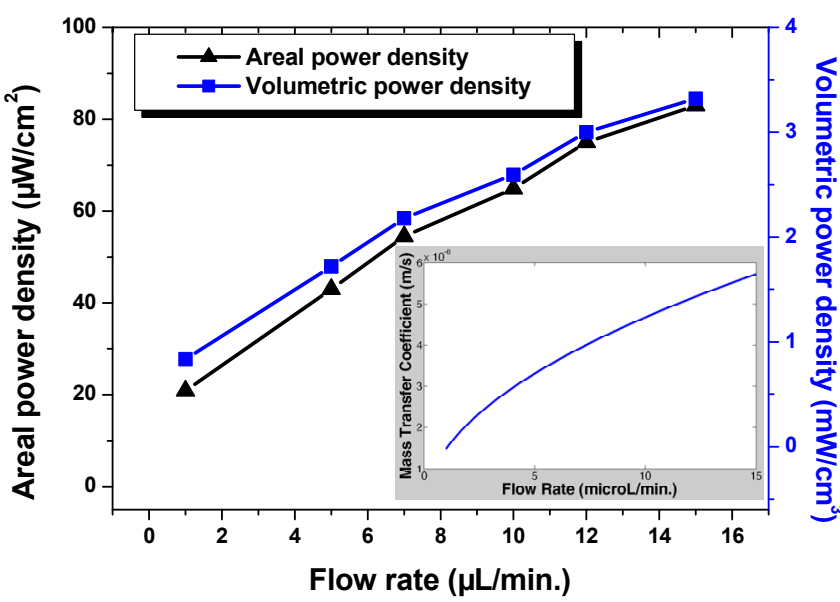

Figure 6: Areal and volumetric power densities as a function of flow rate (inset: calculated mass transfer coefficient versus flow rate)

The internal resistances are calculated by linearly fitting the ohmic region of each output voltage versus areal current density curve in figure 4 , and the internal resistance of $\mu \mathrm{L}$-scale MFCs having flow rate of $5,7,10,12$, and $15 \mu \mathrm{L} / \mathrm{min}$ are $2.76,2.52,1.96$, 1.73 , and $1.39 \mathrm{k} \Omega$, respectively. This also supports higher flow rates incur higher mass transfer, thereby lowering the internal resistance and improving the areal power density. The highest areal and volumetric power densities of $\mu \mathrm{L}$-scale MFCs are to be measured as $83 \mu \mathrm{W} / \mathrm{cm}^{2}$ and $3,320 \mu \mathrm{W} / \mathrm{cm}^{3}$, the highest among all $\mu \mathrm{L}$-scale MFCs to date.

Columbic efficiency (CE) is a measure of how efficiently a MFC harvests electrons. Low CE is another challenge of $\mu \mathrm{L}$-scale MFCs. The maximum CE reported by $\mu \mathrm{L}$-scale MFCs is $31 \%$, significantly lower than that of macro- and meso-scale MFCs, which often reach a $\mathrm{CE}$ of higher than $80 \%$. The low $\mathrm{CE}$ is believed to be primarily due to high oxygen leakage into the anode chamber [9].

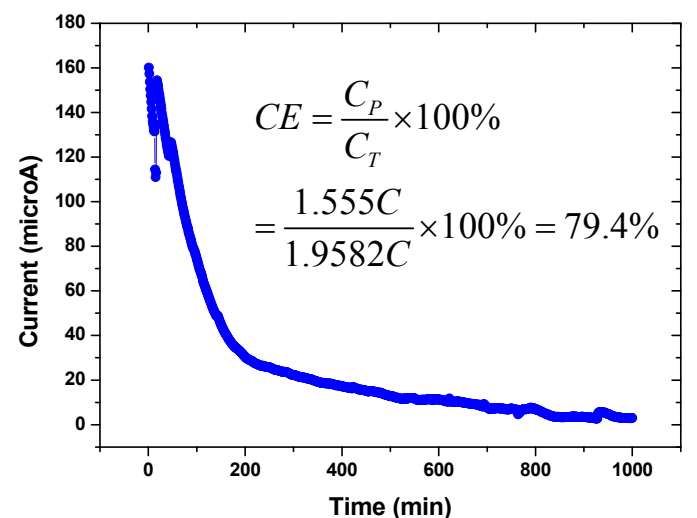

Figure 7: Columbic efficiency (CE) measurement, CE calculation is embedded into the figure.

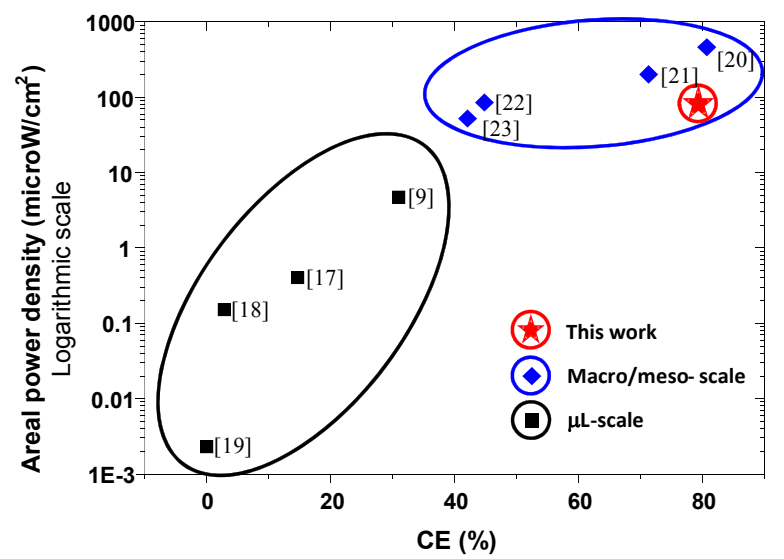

Figure 8: A comparison of areal power density and CE of this work with existing macro-/meso- and $\mu L$-scale MFCs; the power density and $C E$ of this work is substantially higher than those of $\mu L$-scale MFCs and is comparable with those of macro-/meso-scale MFCs.

$\mathrm{CE}$ of the $\mu \mathrm{L}$-scale MFC was measured by integrating current profiles over the time, as shown in figure 7 [16]. The CE is calculated to be $79.4 \%$ (figure 7 inset), significantly higher than that of reported $\mu \mathrm{L}$-scale MFCs, which are generally between $0.03-$ $31 \%$, and it is comparable to that of macro-/meso-scale MFCs (figure 8). Specifications and performance matrix of prior art and this work on $\mu \mathrm{L}$-scale MFCs are summarized in table 1.

Table 1: Summary table of this work and prior art.

\begin{tabular}{|c|c|c|c|c|c|}
\hline & {$[9]$} & {$[10]$} & {$[20]$} & {$[21]$} & $\begin{array}{c}\text { This } \\
\text { work }\end{array}$ \\
\hline Anode volume $[\mu \mathrm{L}]$ & 4.5 & 25 & 0.1 & 1.5 & $\mathbf{1 0 0}$ \\
\hline Anode area $\left[\mathrm{cm}^{2}\right]$ & 2.25 & 1 & 0.12 & 1.2 & $\mathbf{4}$ \\
\hline $\begin{array}{c}\text { Internal resistance } \\
{[\mathrm{k} \Omega]}\end{array}$ & 10 & 32 & 25 & 30 & $\mathbf{1 . 3 9}$ \\
\hline $\mathrm{P}_{\text {areal }}\left[\mu \mathrm{W} / \mathrm{cm}^{2}\right]$ & 4.7 & 33 & 0.4 & 1.5 & $\mathbf{8 3}$ \\
\hline $\mathrm{P}_{\text {volumetric }}\left[\mu \mathrm{W} / \mathrm{cm}^{3}\right]$ & 2333 & 667 & 4.24 & 15.3 & $\mathbf{3 3 2 0}$ \\
\hline $\mathrm{CE}[\%]$ & 31 & $\mathrm{~N} / \mathrm{A}$ & 14.7 & 2.8 & $\mathbf{7 9 . 4}$ \\
\hline
\end{tabular}

One of challenges in our $\mu \mathrm{L}$-scale MFC is that ferricyanide etches the $\mathrm{Cr} / \mathrm{Au}$ cathode, resulting in a short lifetime. After 45 days, a large portion of the cathode and electrical route were etched away, and consequently lowered power and current densities. The etched cathode was replaced and the $\mu \mathrm{L}$-scale MFC was re-assembled to operate. The current profile, figure 9 , shows it took five days to recover the maximum current density since the cathode 
replacement.

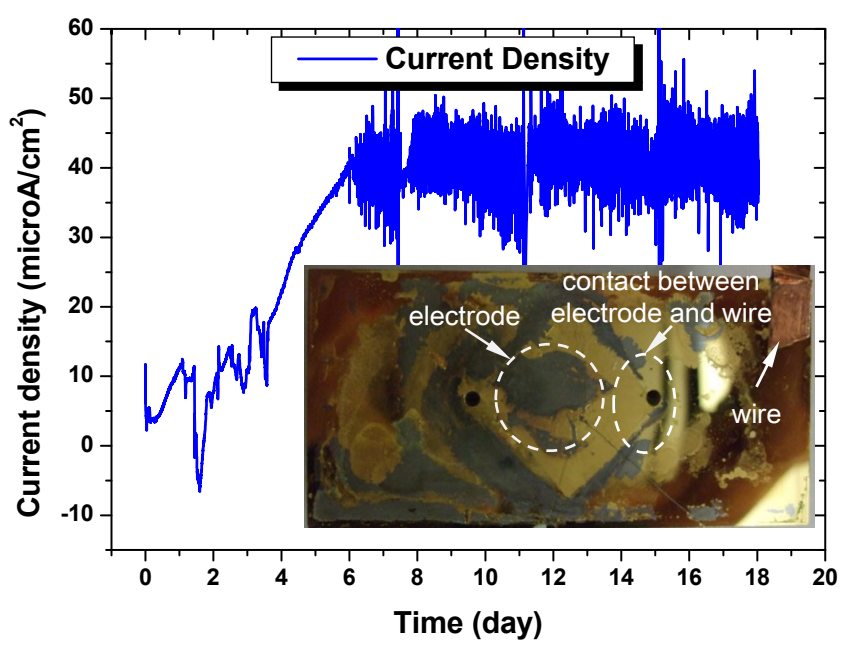

Figure 9: Current density versus time after cathode replacement and re-assembly, it took five days to recover the maximum current density, inset: photograph showing a large portion of cathode and electrical route etched by ferricyanide after 45 days.

\section{CONCLUSION}

In summary, this study presents the scaling effect on the characteristic length of a $\mu \mathrm{L}$-scale MFC. The scaling effect predicts the power density, especially volumetric power density, of a $\mu \mathrm{L}$-scale MFC increases, via improving mass transfer of anolyte/catholyte. A $\mu \mathrm{L}$-scale MFC was built to demonstrate areal and volumetric power densities of $83 \mu \mathrm{W} / \mathrm{cm}^{2}$ and $3,320 \mu \mathrm{W} / \mathrm{cm}^{3}$, respectively and a CE of $79.4 \%$, which are the highest among all previously reported $\mu \mathrm{L}$-scale MFCs.

\section{ACKNOWLEDGEMENT}

The authors thank Dr. Parameswaran for providing Geobacteraceae-enriched culture. Travel support has been generously provided by the Transducer Research Foundation.

\section{REFERENCES}

[1] Y. Ahn and B.E. Logan. "Effectiveness of domestic wastewater treatment using microbial fuel cell at ambient and mesophilic temperatures", Bioresource Technology, 101, pp. 469-475 (2010).

[2] Y. Feng, X. Wang, B.E. Logan and H. Lee. "Brewery wastewater treatment using air-cathode microbial fuel cells", Appl Microbiol Biotechnol, 78, pp. 873-880 (2008).

[3] B.E. Logan. "Scaling up microbial fuel cells and other bioelectrochemical systems", Appl Microbiol Biotechnol, 85, pp. 1665-1671 (2010).

[4] J.M. Morris and S. Jin. "Feasibility of using microbial fuel cell technology for bioremediation of hydrocarbons in groundwater", J. Environ. Sci. Health Part A Tox. Hazard. Subst. Environ. Eng., 43, pp. 18-23 (2008).

[5] T. Catal, Y. Fan, K. Li, H. Bermek and H. Liu. "Effects of furan derivatives and phenolic compounds on electricity generation in microbial fuel cells", J. Power Sources, 180, pp. 162-166 (2008).

[6] J.K. Jang, I.S. Chang, H. Moon, K.H. Kang and B.H. Kim. "Nitrilotriacetic acid degradation undermicrobial fuel cell environment", Biotechnol. Bioeng., 95, pp. $772-774$ (2006).

[7] L.M. Tender, S.A. Gray, E. Groveman, D.A. Lowy, P. Kauffman, J. Melhado, R.C. Tyce, D. Flynn, R. Petrecca and J. Dobarro.
"The first demonstration of a microbial fuel cell as viable power supply: powering a meteorological buoy", J. Power Sources, 179, pp. 571-575 (2008).

[8] Y. Gong, S.E. Radachowsky, M. Wolf, M.E. Nielsen, P.R. Girguis and C.E. Reimers. "Benthic microbial fuel cell as direct power source for an acoustic modem and seawater oxygen/temperature sensor system", Environ. Sci. Technol., 45, pp. 5047-5053 (2011).

[9] S. Choi, H.S. Lee, Y. Yang, P. Parameswaran, C.I. Torres, B.E. Rittmann and J. Chae. "A $\mu \mathrm{L}$-scale micromachined microbial fuel cell having high power density", Lab Chip, 11, 1110 (2011).

[10] S. Choi and J. Chae. "An array of microliter-sized microbial fuel cells generating $100 \mu \mathrm{W}$ of power", Sensors and Actuators: A., 177, pp. 10-15 (2012).

[11] F. Qian and D.E. Morse. "Miniaturizing microbial fuel cells", Trends in Biotechnology, 29, pp. 62-69 (2011).

[12] C.I. Torres, A.K. Marcus, H.S. Lee, P. Parameswaran, R.K. Brown and B.E. Rittmann. "A kinetic perspective on extracellular electron transfer by anode-respiring bacteria", FEMS Microbiol Rev, 34, pp. 3-17 (2010).

[13] N.S. Malvankar, V. Madeline, K.P. Nevin, A.E. Franks, L. Ching, B.C. Kim, K. Inoue, T. Mester, S.F. Kovalla, J.P. Johnson, V.M. Rotello, M.T. Tuominen and D.R. Lovely. "Tunable metallic-like conductivity in microbial nanowire networks", Nature Nanotechnology, 6, pp. 573-579 (2011).

[14] H. Lee, P. Parameswaran, A.K. Marcus, C.I. Torres and B.E. Rittmann. "Evaluation of energy-conversion efficiencies in microbial fuel cells (MFCs) utilizing fermentable and non-fermentable substrates", Water Research, 42, pp. 1501-1510 (2008)

[15] L.M. Prescott, D.A. Klein, and J.P. Harley. Microbiology, $5^{\text {th }}$ edition, The McGraw-Hill Companies, New York, 2002.

[16] B.E. Logan, B. Hamelers, R. Rozendal, U. Schröder, J. Keller, S. Freguia, P. Alterman, V. Verstraete and K. Rabaey. "Microbial fuel cells: methodology and technology", Environ. Sci. Technol, 40, pp. 5081-5092 (2006).

[17] C. Siu and M. Chiao. "A Microfabricated PDMS Microbial Fuel Cell”, J. Microelectromech. Syst., 17, pp. 1329-1341 (2008).

[18] F. Qian, M. Baum, Q. Gu and D.E. Morse. "A 1.5 $\mu 1$ microbial fuel cell for on-chip bioelectricity generation”, Lab Chip, 9, pp. 3076-3081 (2009).

[19] M. Chiao, K.B. Lam and L. Lin. "Micromachined microbial and photosynthetic fuel cells", J. Micromech. Microeng., 16, pp. 2547-2553 (2006).

[20] K. Rabaey, N. Boon, S.D. Siciliano, M. Verhaege and W. Verstraete. "Biofuel cells select for microbial consortia that self-mediate electron transfer", Appl. Environ. Microbiol., 70, pp. 5373-5382 (2004).

[21] Y. Fan, H. Hu and H. Liu. "Enhanced coulombic efficiency and power density of air-cathode microbial fuel cells with an improved cell configuration", Journal of Power Sources, 171, pp. 348-354 (2007).

[22] H. Liu, S. Cheng, L. Huang and B.E. Logan. "Scale-up membrane-free single chamber microbial fuel cells", Journal of Power Sources, 179, pp. 274-279 (2008).

[23] H. Liu and B.E. Logan. "Electricity generation using an air-cathode single chamber microbial fuel cell in the presence and absence of a proton exchange membrane", Environ. Sci. Technol., 38, pp. 4040-4046 (2004).

\section{CONTACT}

*J. Chae, tel: +1-480-965-2082; Junseok.Chae@asu.edu 